\title{
A novel atlas of gene expression in human skeletal muscle reveals molecular changes associated with aging
}

Jing Su ${ }^{1 \dagger}$, Carl Ekman ${ }^{2+}$, Nikolay Oskolkov ${ }^{2}$, Leo Lahti ${ }^{3}$, Kristoffer Ström ${ }^{2,4}$, Alvis Brazma ${ }^{1}$, Leif Groop², Johan Rung ${ }^{1,5}$ and Ola Hansson ${ }^{2^{*}}$ (i)

\begin{abstract}
Background: Although high-throughput studies of gene expression have generated large amounts of data, most of which is freely available in public archives, the use of this valuable resource is limited by computational complications and non-homogenous annotation. To address these issues, we have performed a complete re-annotation of public microarray data from human skeletal muscle biopsies and constructed a muscle expression compendium consisting of nearly 3000 samples. The created muscle compendium is a publicly available resource including all curated annotation. Using this data set, we aimed to elucidate the molecular mechanism of muscle aging and to describe how physical exercise may alleviate negative physiological effects.

Results: We find 957 genes to be significantly associated with aging $(p<0.05$, FDR $=5 \%, n=361)$. Aging was associated with perturbation of many central metabolic pathways like mitochondrial function including reduced expression of genes in the ATP synthase, NADH dehydrogenase, cytochrome $C$ reductase and oxidase complexes, as well as in glucose and pyruvate processing. Among the genes with the strongest association with aging were $\mathrm{H} 3$ histone, family $3 \mathrm{~B}\left(\mathrm{H} 3 \mathrm{FB}, p=3.4 \times 10^{-13}\right)$, AHNAK nucleoprotein, desmoyokin (AHNAK, $p=6.9 \times 10^{-12}$ ), and histone deacetylase $4\left(\right.$ HDAC4, $\left.p=4.0 \times 10^{-9}\right)$. We also discover genes previously not linked to muscle aging and metabolism, such as fasciculation and elongation protein zeta 2 (FEZ2, $\left.p=2.8 \times 10^{-8}\right)$. Out of the 957 genes associated with aging, $21(p<0.001$, false discovery rate $=5 \%, n=116)$ were also associated with maximal oxygen consumption $\left(\mathrm{VO}_{2 \mathrm{MAX}}\right)$. Strikingly, 20 out of those 21 genes are regulated in opposite direction when comparing increasing age with increasing $\mathrm{VO}_{2 \mathrm{MAX}}$.
\end{abstract}

Conclusions: These results support that mitochondrial dysfunction is a major age-related factor and also highlight the beneficial effects of maintaining a high physical capacity for prevention of age-related sarcopenia.

Keywords: Skeletal muscle, Expression, Microarray, Aging, Mitochondrial dysfunction, Exercise

\section{Background}

Aging profoundly affects skeletal muscle, including loss of muscle mass and strength and increasing the levels of fat and connective tissue [1]. This condition, often termed age-related sarcopenia, leads to a variety of physical conditions that reduce life quality and overall health

\footnotetext{
*Correspondence: Ola.Hansson@med.lu.se

${ }^{\dagger}$ Equal contributors

${ }^{2}$ Lund University Diabetes Center, Department of Clinical Sciences, Diabetes and Endocrinology, Skåne University Hospital Malmö, Lund University, Malmö 20502, Sweden

Full list of author information is available at the end of the article
}

in aging individuals $[2,3]$. As we age, we lose approximately $1 \%$ of leg lean mass per year and approximately $2.5-4 \%$ in leg strength, men to a higher extent than women [4]. This indicates that sarcopenia is not only a matter of loss of muscle mass but rather a concomitant loss of muscle mass and a decline of muscle quality. In order to efficiently delay the onset and severity of sarcopenia, it is crucial to more in detail describe the molecular mechanisms causing this physiological deterioration of muscle function.

\section{Biomed Central}

(c) 2015 Su et al. Open Access This article is distributed under the terms of the Creative Commons Attribution 4.0 International License (http://creativecommons.org/licenses/by/4.0/), which permits unrestricted use, distribution, and reproduction in any medium, provided you give appropriate credit to the original author(s) and the source, provide a link to the Creative Commons license, and indicate if changes were made. The Creative Commons Public Domain Dedication waiver (http:// creativecommons.org/publicdomain/zero/1.0/) applies to the data made available in this article, unless otherwise stated. 
In one of the largest previous studies on gene expression in aging muscle [5], muscle biopsies from 81 individuals were investigated. Zahn et al. described a 250-gene signature for muscle aging, compared this to age-associated gene regulation in other tissues and found increased expression of pathways regulating cell growth, complement activation, and ribosomal and extracellular matrix genes and decreased expression of genes for chloride transport and mitochondrial oxidative phosphorylation (OXPHOS). De Magalhaes and colleagues [6] conducted a metaanalysis of microarray experiments on aging in mice, rats, and humans across a variety of tissues. In this crossspecies, cross-platform analysis, gene orthologues were meta-analyzed for approximately 400 samples, 42 of which were from human skeletal muscle, comparing old to young individuals. They found 73 genes with altered expression, with increased expression of genes involved in inflammation and immune response, and consistent with Zahn et al. reduced expression of genes associated with energy metabolism, particularly mitochondrial genes (accessible through the GenAge database, http://genomics.senescence.info/genes/). It has also been shown that aging individuals have increasing levels of mitochondrial DNA damage leading to reduced expression of genes in the OXPHOS pathway [7]. Taken together, a general finding is that mitochondrial dysfunction is partly responsible for reduced muscle function with aging [8]. Reduced expression of genes in the OXPHOS pathway, including the regulator peroxisome proliferator-activated receptor gamma coactivator alpha $(\mathrm{PGC} 1 \alpha)$, has also been found to be reduced in skeletal muscle from type 2 diabetic patients $[9,10]$, a strongly age-related metabolic disorder. Another central pathway previously associated with muscle aging is the mammalian target of rapamycin (mTOR), including the mTOR complex I (mTORC1) which plays a crucial role in the regulation of translation in skeletal muscle [11]. A metabolic link between mTOR and glycolysis has also been described where low glycolytic flux leads to binding of glyceraldehyde-3-phosphate dehydrogenase (GAPDH) to the mTORC1-regulator Rheb thereby inhibiting mTORC1 signaling and suppression of protein synthesis [12].

To understand more the molecular mechanisms of aging in detail, larger sets of samples are required to provide more power to detect regulatory patterns on the gene level. We and others have previously combined data for studies of global transcriptomic patterns across thousands of samples [13-16], but in this study, we address specific phenotype-related questions for skeletal muscle with a collected compendium of 2852 samples. Reuse of public data is however hampered by the use of different experimental platforms and sample annotation, and analysis is not straightforward when combining such data [17].
Based on this muscle expression compendium, we present the largest study to date of gene expression in human skeletal muscle related to aging. We address the concerns of data heterogeneity by an extensive manual re-annotation of all samples and a variety of computational methods described below. In our meta-analysis, we find 957 genes significantly associated with aging. The data provides substantially more detail to genespecific effects of the transcriptome and shows more widespread regulation of gene expression associated with aging than previously reported. We further study the pleiotropic associations of the 957 genes associated with aging and show for example that 20 out of the 21 aging genes are also associated with physical capacity but regulated in the opposite direction with increased physical capacity as compared to increased age.

The skeletal muscle expression compendium is publicly available at ArrayExpress (http://www.ebi.ac.uk/arrayexpress/) with accession number E-MTAB-1788.

\section{Methods}

\section{Data collection and annotation}

Experiments stored in the ArrayExpress archive [18] were identified by keyword searching aimed at identifying experiments that contained microarrays done on skeletal muscle tissue from living human individuals and with interventions limited to training and glucose/insulin regulation, excluding for example drug treatments. Samples were annotated using the categories and factor values in Table 1.

\section{Preprocessing and quality control}

Data normalization was done on the raw .cel files for HG-U133A and HG-U133 + 2 using Robust Probabilistic Averaging (RPA) $[19,20]$. Custom array definition files were created using the customCDF R/Bioconductor package (v16), removing probes mapping to known SNPs, and summarizing probes for each gene with an ENSG identifier. Quality control was carried out using the R/Bioconductor package array QualityMetrics [21] removing detected outlier arrays.

\section{Statistical analysis}

Linear regression analysis for the effect of age and physical capacity and removal of study effects was carried out using the limma $\mathrm{R} /$ Bioconductor package and the eBayes function. A linear model

$$
x \sim \text { age }+ \text { sex }+ \text { study }
$$

was fitted to the RPA-normalized, gene-summarized data for all genes on each of the two platforms. The "study" parameter was represented by the original ArrayExpress accession number. Model coefficients and 
Table 1 Defined terms and value ranges used to annotate the compendium

\begin{tabular}{|c|c|c|}
\hline Parameter & Value & Arrays \\
\hline \multirow[t]{4}{*}{ Sex } & Male & 1085 \\
\hline & Female & 691 \\
\hline & Mixed & 443 \\
\hline & Unknown & 85 \\
\hline \multirow[t]{4}{*}{ Age } & Age given & 993 \\
\hline & Age group & 642 \\
\hline & Age range & 518 \\
\hline & Unknown age & 151 \\
\hline \multirow[t]{6}{*}{ T2D status } & Non-T2D & 1269 \\
\hline & NGT & 321 \\
\hline & IGT & 86 \\
\hline & IGT or T2D & 89 \\
\hline & $\mathrm{T} 2 \mathrm{D}$ & 124 \\
\hline & Unknown & 415 \\
\hline \multirow[t]{3}{*}{$\mathrm{BMI}$} & BMl given & 207 \\
\hline & BMI group & 637 \\
\hline & BMI unknown & 1460 \\
\hline \multirow[t]{3}{*}{ Physical capacity } & PC given & 175 \\
\hline & PC group & 81 \\
\hline & PC unknown & 2048 \\
\hline \multirow[t]{3}{*}{ Family history of diabetes } & $\mathrm{FH}+$ & 24 \\
\hline & $\mathrm{FH}-$ & 159 \\
\hline & FH unknown & 2121 \\
\hline \multirow[t]{3}{*}{ Muscle type } & Quad & 1970 \\
\hline & Other muscle & 242 \\
\hline & Unknown & 92 \\
\hline \multirow[t]{8}{*}{ Interventions } & Clamp & 316 \\
\hline & Longer training & 158 \\
\hline & Shorter training/damage & 213 \\
\hline & Immobilization 2 days & 72 \\
\hline & Immobilization 4-14 days & 100 \\
\hline & Immobilization 60 days & 170 \\
\hline & Protein intake & 88 \\
\hline & Other & 196 \\
\hline \multirow[t]{3}{*}{ Immobilized/trained } & Trained & 108 \\
\hline & Immobilized & 175 \\
\hline & Acute trained $>24 \mathrm{~h}$ & 106 \\
\hline
\end{tabular}

2852 samples were annotated. As far as possible, exact values were recorded for numerical parameters. For some studies, individual records were not resolvable, and instead a group average and dispersion measure was given T2D type 2 diabetes

$p$ values were estimated using the eBayes function in limma. For genes present on both arrays, the minimum $p$ value and the maximum of the $\beta$ values for the regression slope of the age parameter were calculated. $p$ value correction for false discovery rate $(F D R)<0.05$ was done using the Benjamini-Hochberg method using $N=$ 31,523 (the total number of $p$ values calculated for the two arrays).

To calculate profiles of gene expression as a function of age across the studies, we adjusted the original data for study effects by subtracting the effect quantified in the regression model. For each gene $i$ and sample $j$, we calculated

$$
x i j=c_{i}+\beta_{\text {age }, i} \times \operatorname{age}_{j}+\beta_{\text {sex }, i} \times \operatorname{sex}_{j}+\varepsilon_{i}
$$

where $c_{i}$ is the intercept of the linear regression above, $\beta_{\text {age }}$ and $\beta_{\text {sex }}$ are the slopes for the age and sex factors, and $\varepsilon_{i}$ is the gene-specific residual from the previous regression.

In the analysis of physical capacity, we used 116 samples from the HG-U133 + 2 array with harmonized annotation for physical capacity, measured as $\mathrm{VO}_{2 \mathrm{MAx}}$ in liters per minute to kilogram $(\mathrm{L} /(\min \times \mathrm{kg}))$. For these, we fitted a linear model

$$
x \sim \text { physical capacity }+ \text { Saturday }
$$

to the RPA-normalized, gene-summarized expression data. We estimated $p$ values and regression coefficients for the model using the limma package with the eBayes function, as above.

We tested the significance of the overlap between subsets of the 957 genes with database lists using the hypergeometric test and a background of $N=19,597$ genes.

Differential expression between subjects with type 2 diabetes (T2D) and normal glucose tolerance (NGT) individuals for the 957 age-associated genes was estimated by meta-analysis of three datasets with full annotation for these groups: E-GEOD-18732, E-GEOD-19420, and EGEOD-25462, including 102 T2D and 87 NGT samples. The datasets were individually normalized with RPA and meta-analyzed using the geneMeta R/Bioconductor package (www.bioconductor.org/packages/release/ bioc/html/GeneMeta.html). Association to body mass index (BMI) was calculated by retrieving all samples within the seven selected datasets with annotation for BMI from the HG-U133 + 2 arrays and normalized as a single dataset using RPA, followed by a linear regression for BMI adjusted for sex and study, as identified by ArrayExpress accession number and analogously as described for age and physical capacity.

\section{Comparison with public RNA sequencing data}

RNA sequencing expression data on human skeletal muscles from $n=157$ donors from Genotype-Tissue Expression (GTEx) project (http://www.gtexportal.org/) were used [22]. Across-samples normalization was performed using the TMM normalization method [23]. 
Association of gene expression for each gene with age was calculated with linear regression using an additive model adjusted for gender. The obtained $p$ values were FDR corrected for multiple testing (FDR $<0.05$, Benjamini-Hochberg). All calculations were done using $\mathrm{R}$ language for statistical computations.

\section{Results}

\section{Building the skeletal muscle data compendium}

From ArrayExpress [18], microarray datasets from human skeletal muscle biopsies were selected and manually curated based on the original publications, including available supplemental data (see "Methods" section). The selected experiments contain data from 2852 microarrays from 20 different array platforms (Figure S1 in Additional file 1). Affymetrix-manufactured arrays dominate, represented by 11 different array types and in total 2475 arrays. Using a controlled vocabulary, sample and experimental parameters selected for reannotation were defined. We retrieved the original papers along with supplemental material to re-annotate each microarray using our newly defined parameters and their value ranges (Table 1). To define a generic control set, representing a normal, healthy population, a set of 1188 "super controls" were selected. In this group, samples were excluded if the individual had any kind of disease, was obese (BMI > 30), or was subjected to any severe intervention.

To avoid the strong bias introduced by differences in individual probe sequences when combining data from different array platforms [24], we restricted this study to data from each platform independently. We used a subset of the compendium based on the two most common platforms: 568 arrays from the Affymetrix HG-U133A, and 1174 arrays from the $\mathrm{HG}-\mathrm{U} 133+2$ platform. The probe effects were addressed by normalizing each dataset with RPA $[19,20]$, which models the affinity of each individual probe, assuming it to be a stochastic variable with a normal distribution with probe set-specific mean and variance rather than a constant, as in many other normalization methods including RMA and MAS5. To avoid biases introduced by genetic diversity in the studied individuals, we removed all probes mapping to known human SNPs with a minor allele frequency higher than $5 \%$ in a Western European population. Out of 604,258 probes on the HG-U133 + 2 array, 4840 probes were removed; on the HG-133A array, 2157 out of 247,965 probes were removed. Oligonucleotide probes were summarized to gene level probe sets rather than transcript specific ones, also to minimize biases introduced by probe sequences and their representation on different arrays. After quality control [21], 1236 arrays from the two platforms remained: 758 from HG-U133 + 2 and 485 from HG-U133A. The two resulting data matrices contain data for 19,597 genes tested on the HG-U133 + 2 array and a subset of 11,926 of these on the HG-U133A array. The two resulting cross-study data matrices are also available from ArrayExpress, accession number E-MTAB-1788.

These comprehensive data sets represent comparable human skeletal muscle expression data over a vast array of different experimental conditions. In order to identify constitutively expressed genes, we analyzed the variance of expression only removing the study effect. The genes with most stable expression are presented in Table S1 (see Additional file 1) and are not likely to be influenced by the experimental conditions. The most stable genes found were myoglobin (MB), GAPDH, and alpha 1 actin (ACTA1) and could serve as candidates for "housekeeping" endogenous control genes in quantitative real-time PCR experiments.

\section{Expression levels of $\mathbf{9 5 7}$ genes are associated with age}

We selected a subset of 361 arrays from the compendium to study the effect of aging on gene expression, i.e., 211 arrays from the HG-133A array and 150 from the HG$\mathrm{U} 133+2$ array that had specific annotation of age and gender, ranging from $<1$ year up to 83-year-old individuals (Figure S2 in Additional file 1). Using a linear model with sex and study ID as covariates, 957 genes were significantly associated with age $(p<0.05$, Benjamini-Hochberg correction for multiple testing) (top-50 genes are shown in Table 2). Of these, 484 were upregulated and 473 downregulated with increasing age. We verify the removal of study effects by principal component analysis (PCA) before and after study adjustment. Whereas samples from the same study primarily cluster together in the PCA of the unadjusted dataset, this effect is removed in the adjusted one (Fig. 1). Similarly, we use PCA to verify the absence of gender biases in the dataset after the adjustment for study effects (Figure S3 in Additional file 1). A significant overlap $\left(N=13, p=1.0 \times 10^{-5}\right)$ and complete concordance for the direction of the expression for all 13 genes found in our data set out of the 73 genes detected in the multispecies de Magalhaes study [6] were observed. Twenty-five of the 957 genes are reported in the GenAge database of 288 genes linked to aging, an overlap of the two lists which is significant at $p=0.0020$ using a hypergeometric test. The GenAge database has also collected and curated a list of genes in loci detected in genomewide association studies for longevity. They report 886 genes, 353 of which were significantly associated in the original studies. Out of this list, we detect an overlap of 25 out of 957 genes $(p=0.024)$. Seventeen of the 957 aging genes have been previously reported in the top 250 genes by the Zahn study [5] (overlap $p=0.065$ ). Using publicly available RNA sequencing data $(n=157)$ from the GTEx project (http://www.gtexportal.org/), 91 genes out of the 
Table 2 Top 50 genes significantly associated with age across 361 samples

\begin{tabular}{|c|c|c|}
\hline Gene & $\operatorname{Min}(p)$ & $\operatorname{Max}|\beta|$ \\
\hline $\mathrm{H} 3 \mathrm{~F} 3 \mathrm{~B}$ & $3.39 \mathrm{E}-13$ & 0.0098 \\
\hline AHNAK & $6.87 \mathrm{E}-12$ & 0.0086 \\
\hline HOXB2 & $1.01 \mathrm{E}-11$ & -0.0184 \\
\hline CRIM1 & $5.34 \mathrm{E}-11$ & 0.0124 \\
\hline NAP1L1P3 & $9.74 \mathrm{E}-11$ & 0.0154 \\
\hline ARFGAP2 & $3.56 \mathrm{E}-10$ & 0.0069 \\
\hline WDR6 & 4.47E-10 & 0.0069 \\
\hline DLEU1 & 8.61E-10 & -0.0117 \\
\hline USP6 & $1.43 \mathrm{E}-09$ & 0.0133 \\
\hline TCF25 & 2.70E-09 & 0.0064 \\
\hline SCN4B & 3.13E-09 & -0.0289 \\
\hline ZNF274 & 3.87E-09 & 0.0129 \\
\hline HDAC4 & 4.04E-09 & 0.0155 \\
\hline SH3BP5 & 5.04E-09 & 0.0114 \\
\hline SART3 & 5.32E-09 & 0.0050 \\
\hline CASC3 & $9.73 \mathrm{E}-09$ & 0.0061 \\
\hline CIRBP & 1.14E-08 & 0.0091 \\
\hline $\mathrm{HIST} 1 \mathrm{H} 2 \mathrm{BN}$ & 1.49E-08 & -0.0065 \\
\hline FUBP1 & $1.74 \mathrm{E}-08$ & 0.0058 \\
\hline FAM171A1 & $1.94 \mathrm{E}-08$ & -0.0113 \\
\hline NPPA & $1.97 \mathrm{E}-08$ & -0.0048 \\
\hline TMEM59L & $2.39 \mathrm{E}-08$ & -0.0080 \\
\hline UBE2O & 2.79E-08 & -0.0060 \\
\hline FEZ2 & $2.83 \mathrm{E}-08$ & 0.0126 \\
\hline $\mathrm{ALS} 2 \mathrm{CL}$ & 3.15E-08 & -0.0063 \\
\hline C1S & $3.22 \mathrm{E}-08$ & 0.0137 \\
\hline RXRG & $3.23 \mathrm{E}-08$ & -0.0095 \\
\hline NT5C2 & $3.64 \mathrm{E}-08$ & 0.0115 \\
\hline TRMT112 & 4.42E-08 & 0.0116 \\
\hline PRNP & $4.68 \mathrm{E}-08$ & 0.0094 \\
\hline NOL9 & $6.31 \mathrm{E}-08$ & 0.0049 \\
\hline RBM10 & $6.66 \mathrm{E}-08$ & 0.0056 \\
\hline ANP32B & $6.71 \mathrm{E}-08$ & 0.0092 \\
\hline TOMM40L & $6.74 \mathrm{E}-08$ & -0.0144 \\
\hline HTR5A & 7.21E-08 & -0.0051 \\
\hline SEC24C & 7.78E-08 & 0.0060 \\
\hline BUB3 & 7.98E-08 & 0.0036 \\
\hline DAAM2 & 8.92E-08 & -0.0091 \\
\hline HSPA1A & 8.93E-08 & 0.0091 \\
\hline SEZ6L2 & $9.12 \mathrm{E}-08$ & -0.0046 \\
\hline MRPL4 & $9.38 \mathrm{E}-08$ & -0.0080 \\
\hline CMC2 & $1.04 \mathrm{E}-07$ & -0.0091 \\
\hline NR1D1 & $1.04 \mathrm{E}-07$ & -0.0054 \\
\hline
\end{tabular}

Table 2 Top 50 genes significantly associated with age across 361 samples (Continued)

\begin{tabular}{lll}
\hline ENDOG & $1.11 \mathrm{E}-07$ & -0.0126 \\
MRPL48 & $1.25 \mathrm{E}-07$ & -0.0066 \\
FRAT2 & $1.31 \mathrm{E}-07$ & -0.0064 \\
SYNRG & $1.31 \mathrm{E}-07$ & 0.0040 \\
PPIC & $1.38 \mathrm{E}-07$ & -0.0076 \\
POMT1 & $1.47 \mathrm{E}-07$ & 0.0061 \\
DECR2 & $1.65 \mathrm{E}-07$ & 0.0043 \\
\hline
\end{tabular}

The minimum $p$ and maximum $\beta$ values were calculated for genes present in both array datasets, adjusted for sex and study effect. A positive $\beta$ value implicates increasing gene expression with age. For the full list of 957 genes, see Table S2 in Additional file 2

957 were found associated with age, a significant overlap at $p=2.2 \times 10^{-16}$.

The genes with the strongest association to aging in the current study are H3F3B $\left(p=3.4 \times 10^{-13}\right)$ and AHNAK $\left(p=6.9 \times 10^{-12}\right)$, both showing increased expression with increased age. AHNAK is a large protein localized to the sarcomere of skeletal muscle and increased expression of AHNAK with aging is in line with the study by de Magalhaes et al. [6]. Increased expression of AHNAK has previously also been associated with a low $\mathrm{VO}_{2 \mathrm{MAX}}$ and poor muscle fitness [25]. The two genes most strongly showing reduced expression with increasing age are homeobox B2 (HOXB2, $p=1.0 \times 10^{-11}$ ) and deleted in lymphocytic leukemia 1 (DLEU1, $p=8.6 \times 10^{-10}$ ). The full list of 957 genes is available in Table S2 (see Additional file 2).

\section{Aging significantly alters genes involved in inflammation} and mitochondrial metabolism

We analyzed the lists of 484 genes upregulated and 473 downregulated with aging for enrichment of specific pathways and processes using gene set enrichment analysis (GSEA) (Table 3) [9]. We find enrichment of genes with increased expression in six pathways, connected to the complement system, indicating an inflammatory response with aging ( $p<0.05$, Bonferroni adjusted). This is in line with Zahn et al. that also reported increased expression of genes in the complement system with aging [5]. Thirteen pathways were enriched in genes with decreased expression associated with increasing age $(p<0.05$, Bonferroni adjusted). Eight of these represent mitochondrial components, supporting a perturbation of mitochondrial function with aging. Four groups connected to metabolism were also found, indicating reduced expression of genes in the electron transport chain (ETC)/OXPHOS pathway, in the citric acid/tricarboxylic acid cycle (TCA), and in pyruvate metabolism. We observe significant downregulation with increasing age of all four major complexes of the ETC 

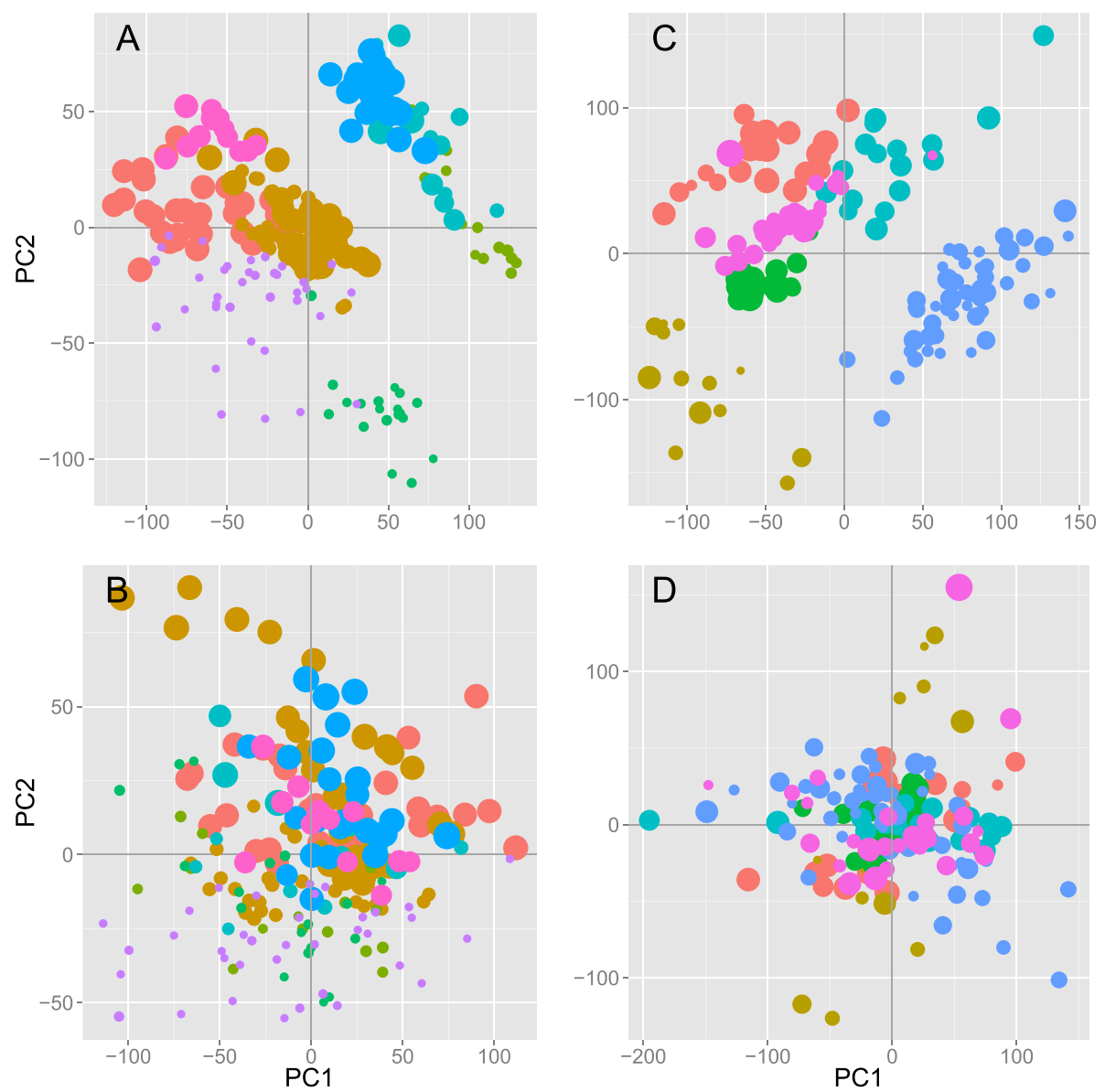

Fig. 1 Principal component analysis of the 211 HG-U133A arrays, before (a) and after (b) removal of study effects and corresponding plots for the 150 HG-U133 + 2 arrays (c and $\mathbf{d}$ ). Different studies (identified by database accession numbers) are represented with different colors, and increasing age of the individual from whom the biopsy was taken is indicated by the increasing dot size. The relatively strong study effect seen even after normalization is removed after the adjustment

located in the inner mitochondrial membrane (Figure S4 in Additional file 1). Subunits of NADH dehydrogenase (NDUFAF5, $p=1.0 \times 10^{-4}$; NDUFS3, $p=8.8 \times 10^{-5}$ ), cytochrome c reductase (UQCR10, $p=2.6 \times 10^{-4}$; UQCR11, $\left.p=7.7 \times 10^{-4}\right)$ and oxidase (COX10, $p=4.3 \times 10^{-5}$; COX4I1, $p=1.7 \times 10^{-4}$; COX7B, $p=3.1 \times 10^{-4}$; COX7C, $p=6.1 \times 10^{-4}$; COX5B, $p=1.1 \times 10^{-3}$ ), and ATP synthase (ATP5G3, $p=1.1 \times 10^{-6}$; ATPAF1, $p=3.6 \times 10^{-5}$; ATP5G1, $p=8.0 \times 10^{-5}$; ATP5C1, $p=2.0 \times 10^{-4}$; COX10, $p=4.3 \times$ $10^{-5}$ ) are all downregulated with increasing age. We also find that the expression of $\mathrm{C}-\mathrm{x}(9)-\mathrm{C}$ motif containing 2 (CMC2) is decreased with aging $\left(p=1.0 \times 10^{-7}\right)$. CMC2 is required for respiratory growth, and mutants with $\mathrm{CMC} 2$ deletion are unable to assemble the cytochrome c oxidase complex [26]. In the pyruvate dehydrogenase complex (PDC), proteins $\mathrm{A} 1, \mathrm{~B}$, and $\mathrm{X}\left(p=4.1 \times 10^{-6} ; 4.2 \times 10^{-5}\right.$; $1.3 \times 10^{-3}$ ) show reduced expression with aging. In connection to carbohydrate metabolism, the expression of 6-phosphofructo-2-kinase/fructose-2,6-biphosphatase 1
(PFKFB1) is increased with aging $\left(p=9.4 \times 10^{-5}\right)$. Furthermore, glucose uptake through GLUT4 in skeletal muscle is known to be dependent on TBC1 Domain Family Member 1 (TBC1D1) [27, 28], the expression of which is decreased with aging $\left(p=3.6 \times 10^{-4}\right)$.

\section{High physical capacity counteracts age-related changes in muscle expression}

Decline in muscle mass and performance with aging can be prevented by exercise. Therefore, we explored whether expressions of any of the genes associated with aging also were influenced by physical capacity assessed as $\mathrm{VO}_{2 \mathrm{MAX}}$.

In a subset of 116 samples with information on $\mathrm{VO}_{2 \mathrm{MAX}}$, we find 39 genes associated with physical capacity (FDR $<0.05$, Benjamini-Hochberg, Table 4), but given the relatively low number of samples included in the $\mathrm{VO}_{2 \mathrm{MAx}}$ analysis, we restricted our analysis to the 957 genes associated with age. Of them, 21 were also 
Table 3 Gene set enrichment analysis for the 484 genes upregulated with age and the 473 downregulated

\begin{tabular}{|c|c|c|c|}
\hline Upregulated sets & ES & NES & FDR q value \\
\hline KEGG_COMPLEMENT_AND_COAGULATION_CASCADES & 0.80 & 2.32 & 0.0047 \\
\hline REACTOME_INITIAL_TRIGGERING_OF_COMPLEMENT & 0.89 & 2.18 & 0.0133 \\
\hline REACTOME_COMPLEMENT_CASCADE & 0.89 & 2.15 & 0.0138 \\
\hline BIOCARTA_COMP_PATHWAY & 0.86 & 2.21 & 0.0148 \\
\hline KEGG_SYSTEMIC_LUPUS_ERYTHEMATOSUS & 0.75 & 2.07 & 0.0288 \\
\hline BIOCARTA_CLASSIC_PATHWAY & 0.90 & 2.04 & 0.0361 \\
\hline \multicolumn{4}{|l|}{ Downregulated sets } \\
\hline REACTOME_TCA_CYCLE_AND_RESPIRATORY_ELECTRON_TRANSPORT & -0.76 & -2.90 & 0.0000 \\
\hline MITOCHONDRION & -0.59 & -2.70 & 0.0000 \\
\hline REACTOME_PYRUVATE_METABOLISM_AND_CITRIC_ACID_TCA_CYCLE & -0.81 & -2.48 & 0.0008 \\
\hline MITOCHONDRIAL_ENVELOPE & -0.74 & -2.39 & 0.0010 \\
\hline MITOCHONDRIAL_MEMBRANE & -0.74 & -2.37 & 0.0011 \\
\hline MITOCHONDRIAL_PART & -0.74 & -2.39 & 0.0012 \\
\hline KEGG_PARKINSONS_DISEASE & -0.73 & -2.40 & 0.0013 \\
\hline ORGANELLE_INNER_MEMBRANE & -0.74 & -2.30 & 0.0014 \\
\hline ORGANELLE_ENVELOPE & -0.68 & -2.33 & 0.0015 \\
\hline MITOCHONDRIAL_INNER_MEMBRANE & -0.74 & -2.30 & 0.0015 \\
\hline ENVELOPE & -0.68 & -2.26 & 0.0019 \\
\hline KEGG_OXIDATIVE_PHOSPHORYLATION & -0.64 & -2.23 & 0.0024 \\
\hline REACTOME_PYRUVATE_METABOLISM & -0.81 & -2.22 & 0.0025 \\
\hline COFACTOR_METABOLIC_PROCESS & -0.69 & -2.19 & 0.0037 \\
\hline KEGG_ALZHEIMERS_DISEASE & -0.60 & -2.07 & 0.0117 \\
\hline MITOCHONDRIAL_MEMBRANE_PART & -0.74 & -2.08 & 0.0123 \\
\hline $\begin{array}{l}\text { REACTOME_RESPIRATORY_ELECTRON_TRANSPORT_ATP_SYNTHESIS_BY_CHEMIOSMOTIC_ } \\
\text { COUPLING_AND_HEAT_PRODUCTION_BY_UNCOUPLING_PROTEINS_ }\end{array}$ & -0.70 & -2.02 & 0.0161 \\
\hline REACTOME_GLUCOSE_METABOLISM & -0.70 & -2.03 & 0.0162 \\
\hline REACTOME_GLUCONEOGENESIS & -0.77 & -2.01 & 0.0187 \\
\hline ION_TRANSPORT & -0.82 & -1.99 & 0.0199 \\
\hline COENZYME_METABOLIC_PROCESS & -0.82 & -2.00 & 0.0200 \\
\hline REACTOME_REGULATION_OF_PYRUVATE_DEHYDROGENASE_PDH_COMPLEX & -0.81 & -1.96 & 0.0246 \\
\hline HYDROGEN_ION_TRANSMEMBRANE_TRANSPORTER_ACTIVITY & -0.78 & -1.94 & 0.0283 \\
\hline INORGANIC_CATION_TRANSMEMBRANE_TRANSPORTER_ACTIVITY & -0.78 & -1.91 & 0.0340 \\
\hline ION_TRANSMEMBRANE_TRANSPORTER_ACTIVITY & -0.50 & -1.90 & 0.0378 \\
\hline MONOVALENT_INORGANIC_CATION_TRANSMEMBRANE_TRANSPORTER_ACTIVITY & -0.78 & -1.89 & 0.0380 \\
\hline KEGG_CITRATE_CYCLE_TCA_CYCLE & -0.77 & -1.89 & 0.0385 \\
\hline
\end{tabular}

associated with $\mathrm{VO}_{2 \mathrm{MAx}}$ (Table 5). It is striking, but not unexpected, that aging and increased physical capacity affects gene expression in opposite directions for 20 of the 21 genes. Two of these, the suppressor of cytokine signaling 2 (SOCS2) and the fasciculation and elongation protein zeta 2 (FEZ2) are also associated with BMI (FEZ2: $p_{\mathrm{BMI}}=5.9 \times 10^{-4}, \quad$ SOCS2: $\left.p_{\mathrm{BMI}}=7.3 \times 10^{-4}\right)$; increasing BMI affects gene expression in the same direction as increasing age (FEZ2: $p_{\text {age }}=2.8 \times 10^{-8}$, SOCS2: $p_{\text {age }}=5.5 \times$ $10^{-7}$ ) and in the opposite direction with increased physical capacity (FEZ2: $p_{\mathrm{VO} 2 \max }=3.5 \times 10^{-5}, \mathrm{SOCS} 2: p_{\mathrm{VO} 2 \max }=$ $\left.6.3 \times 10^{-8}\right)($ Fig. 2).

\section{Effect of body mass index and type 2 diabetes on the expression of age-associated genes}

We find that three of the age-associated genes also were associated with T2D, CD163 $\left(p_{\text {age }}=2.2 \times 10^{-4}, p_{\mathrm{T} 2 \mathrm{D}}=\right.$ $\left.2.0 \times 10^{-4}\right), \mathrm{ZNF} 415\left(p_{\text {age }}=8.9 \times 10^{-5}, p_{\mathrm{T} 2 \mathrm{D}}=8.5 \times 10^{-5}\right)$, and GADD $45 \mathrm{~A} \quad\left(p_{\text {age }}=5.4 \times 10^{-4}, \quad p_{\mathrm{T} 2 \mathrm{D}}=1.1 \times 10^{-4}\right)$ (Table 6). Of these, GADD45A and CD163 have 
Table 4 Thirty-nine genes genome-wide significantly associated with physical capacity across 116 samples

\begin{tabular}{|c|c|c|}
\hline Gene & $\operatorname{Min}(p)$ & $\operatorname{Max}|\beta|$ \\
\hline SOCS2 & $6.28 \mathrm{E}-08$ & 0.014 \\
\hline SLC16A10 & $8.53 \mathrm{E}-07$ & -0.024 \\
\hline HOMER1 & $1.02 \mathrm{E}-06$ & -0.018 \\
\hline ZMYND17 & $1.84 \mathrm{E}-06$ & -0.021 \\
\hline $\mathrm{BCKDHB}$ & $3.06 \mathrm{E}-06$ & 0.010 \\
\hline INADL & 4.99E-06 & -0.011 \\
\hline MAST2 & $5.28 \mathrm{E}-06$ & -0.011 \\
\hline $\mathrm{BDH} 1$ & $5.76 \mathrm{E}-06$ & 0.015 \\
\hline ZNF133 & 6.37E-06 & -0.008 \\
\hline METTL7A & $1.22 \mathrm{E}-05$ & -0.022 \\
\hline ZNF57 & 1.30E-05 & 0.011 \\
\hline TMEM56 & $1.61 \mathrm{E}-05$ & -0.021 \\
\hline RALGAPA1 & $1.66 \mathrm{E}-05$ & -0.010 \\
\hline CALU & $1.89 \mathrm{E}-05$ & 0.009 \\
\hline SYNPO2L & $2.11 \mathrm{E}-05$ & -0.014 \\
\hline RP11-304 L19.5.1 & $2.33 \mathrm{E}-05$ & -0.018 \\
\hline AQP1 & $2.79 \mathrm{E}-05$ & 0.014 \\
\hline SCPEP1 & $2.96 \mathrm{E}-05$ & -0.014 \\
\hline KIAA1109 & $3.02 \mathrm{E}-05$ & 0.004 \\
\hline $\mathrm{HYI}$ & $3.46 \mathrm{E}-05$ & -0.008 \\
\hline FEZ2 & $3.46 \mathrm{E}-05$ & -0.020 \\
\hline EIF4E2 & $3.79 \mathrm{E}-05$ & -0.016 \\
\hline LPL & $3.85 \mathrm{E}-05$ & 0.028 \\
\hline ZNRF1 & $3.89 \mathrm{E}-05$ & -0.010 \\
\hline YPEL2 & $3.98 \mathrm{E}-05$ & -0.013 \\
\hline DMRT2 & 4.37E-05 & 0.019 \\
\hline UGGT1 & 4.61E-05 & -0.007 \\
\hline MPP7 & 4.79E-05 & 0.012 \\
\hline SUN1 & 5.37E-05 & -0.008 \\
\hline BRD8 & 5.77E-05 & -0.008 \\
\hline PRKAG3 & $6.04 \mathrm{E}-05$ & -0.025 \\
\hline SLC38A1 & $6.10 \mathrm{E}-05$ & 0.047 \\
\hline ITGA6 & $6.32 \mathrm{E}-05$ & 0.018 \\
\hline CMBL & $6.74 \mathrm{E}-05$ & -0.011 \\
\hline NANOS1 & $8.65 \mathrm{E}-05$ & -0.035 \\
\hline SCGB1D2 & 8.80E-05 & 0.027 \\
\hline MESP1 & 8.97E-05 & -0.008 \\
\hline HSPA2 & $9.31 \mathrm{E}-05$ & -0.022 \\
\hline HEMK1 & $9.56 \mathrm{E}-05$ & -0.008 \\
\hline
\end{tabular}

A positive $\beta$ value implicates increasing gene expression with increased physical capacity, adjusted for study effect

previously been shown to be associated with T2D in GWAS [29, 30]. Interestingly, GADD45A has also been shown to reduce energy production and to stimulate pro-
Table 5 Of the 957 aging genes, 21 were significantly associated with physical capacity across 116 samples

\begin{tabular}{|c|c|c|c|c|}
\hline Gene & $p$ (age) & $p(P C)$ & $\beta$ (age) & $\beta(P C)$ \\
\hline SOCS2 & $5.51 \mathrm{E}-07$ & $6.28 \mathrm{E}-08$ & -0.0034 & 0.0143 \\
\hline SLC16A10 & 0.000785 & $8.53 \mathrm{E}-07$ & 0.00354 & -0.02369 \\
\hline METTL7A & 0.001265 & $1.22 \mathrm{E}-05$ & 0.011168 & -0.02183 \\
\hline CALU & 0.00086 & 1.89E-05 & -0.00311 & 0.009051 \\
\hline FEZ2 & $2.83 \mathrm{E}-08$ & $3.46 \mathrm{E}-05$ & 0.012589 & -0.01958 \\
\hline DMRT2 & 0.000223 & 4.37E-05 & -0.01035 & 0.018518 \\
\hline ITGA6 & 0.000564 & $6.32 \mathrm{E}-05$ & -0.00607 & 0.017743 \\
\hline MESP1 & 0.000246 & 8.97E-05 & -0.00638 & -0.00767 \\
\hline IP6K2 & $2.32 \mathrm{E}-06$ & 0.000112 & 0.005743 & -0.00807 \\
\hline ANKRD27 & 0.000118 & 0.000121 & 0.006005 & -0.02111 \\
\hline $\mathrm{MPC1}$ & 0.000705 & 0.000148 & -0.00478 & 0.010666 \\
\hline PAF1 & $1.07 \mathrm{E}-06$ & 0.000258 & 0.006852 & -0.01292 \\
\hline SLIT2 & 0.000698 & 0.000297 & 0.009127 & -0.01342 \\
\hline DDX24 & $2.01 \mathrm{E}-05$ & 0.000318 & 0.004313 & -0.00869 \\
\hline FAM53C & 0.001351 & 0.000342 & 0.003416 & -0.00845 \\
\hline CPSF7 & 0.000491 & 0.000405 & 0.003669 & -0.00789 \\
\hline DGKD & 0.000456 & 0.000838 & 0.00429 & -0.01153 \\
\hline PHF20 & 0.001338 & 0.000871 & 0.00284 & -0.00665 \\
\hline ABRA & 0.001011 & 0.000952 & 0.014313 & -0.01971 \\
\hline NT5C2 & $3.64 \mathrm{E}-08$ & 0.000954 & 0.011521 & -0.01262 \\
\hline DNAJB2 & $9.22 \mathrm{E}-07$ & 0.000956 & 0.007196 & -0.01217 \\
\hline
\end{tabular}

A positive $\beta$ value implicates increasing gene expression with increased physical capacity, adjusted for study effect

atrophy mechanisms in skeletal muscle [31]. ZNF415 is known to inhibit AP1 and p53 transcriptional activity [32], whereas increased concentration of serum sCD163 is a risk factor for developing T2D [33]. Two of the 957 ageassociated genes were also associated with BMI, i.e., EIF4EBP1 $\left(p_{\mathrm{BMI}}=1.8 \times 10^{-6}\right)$ and AKR1C3 $\left(p_{\mathrm{BMI}}=\right.$ $\left.4.7 \times 10^{-5}\right)$.

\section{Discussion}

Because of differences in annotation standards, analysis of public gene expression data is often hampered by an inability to combine large sets of arrays for new studies. A major benefit of the data set presented here is that it has been manually annotated using a harmonized vocabulary, enabling a more comprehensive and detailed analysis to be performed. We show that through a strong manual curation effort, we could increase the combinability and utility of public data, deriving the until now largest study on aging in human skeletal muscle, and from the same compendium address additional questions regarding physical capacity, BMI, and T2D. This skeletal muscle compendium is publicly available to allow further studies on gene expression in skeletal muscle. 

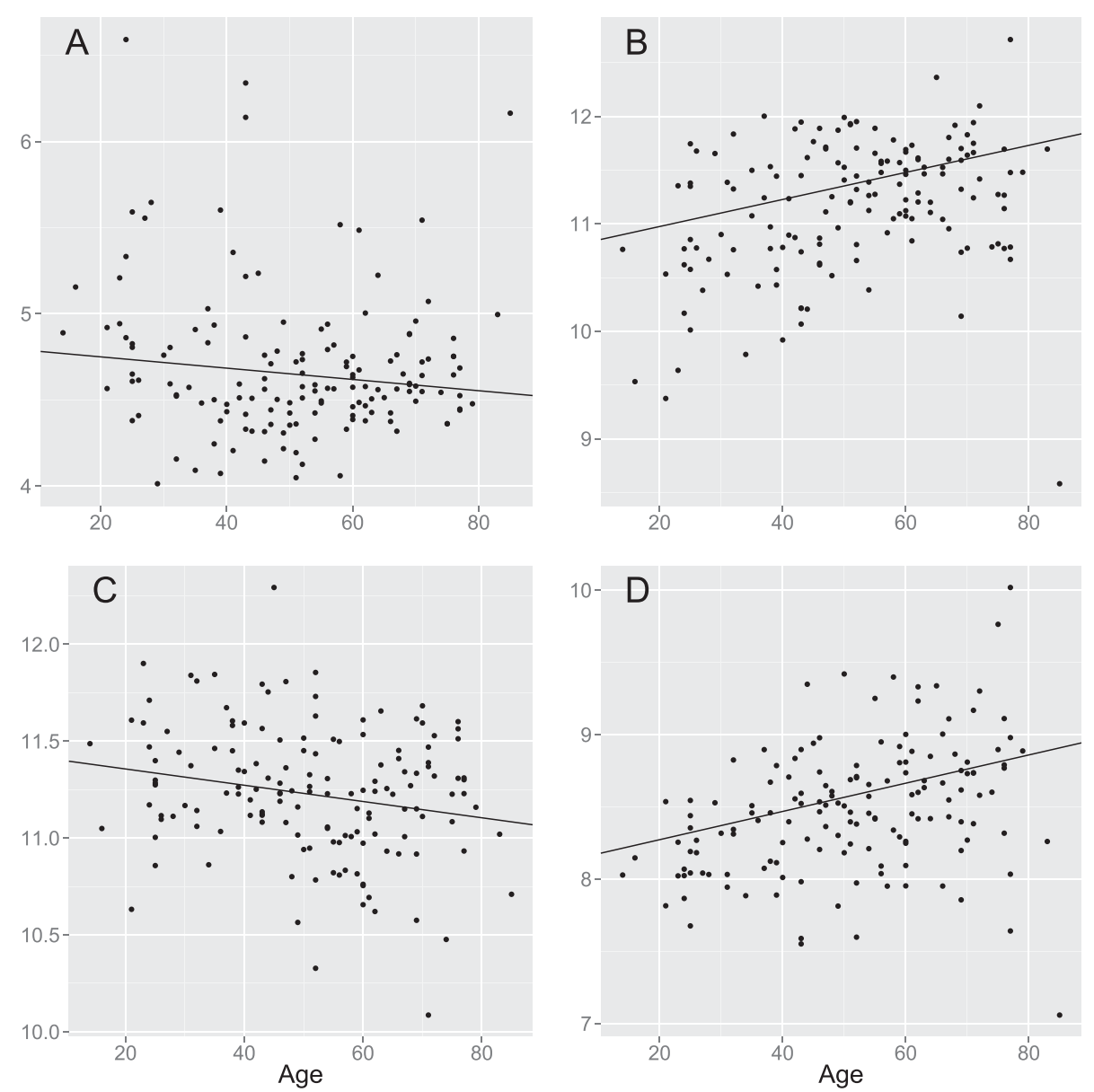

Fig. 2 Expression levels of SOCS2 (a), FEZ2 (b), MPC1 (c), and NT5C2 (d) in relation to age. Batch effect-adjusted expression levels are shown

In the current analysis, we present a detailed description of age-related differences in gene expression in human skeletal muscle and identify 957 genes significantly associated with age. In line with Zahn et al., we find that genes in the complement system show increased expression and mitochondrial genes show decreased expression with aging [5]. Expression of genes in all the major complexes in the ETC, as well as several genes in the PDH complex decreased with aging (Fig. 3). These results together with those of others [34, 35] support the view that elderly subjects have a nearly $50 \%$ lower oxidative capacity per volume of muscle than younger

Table 6 Of the 957 aging genes, three were associated with type 2 diabetes

\begin{tabular}{lllll}
\hline Gene & $p$ (age) & $p$ (T2D) & $\beta$ (age) & $Z$ (T2D) \\
\hline CD163 & 0.00022 & 0.000195 & 0.009341 & 3.725788 \\
ZNF415 & $8.93 \mathrm{E}-05$ & $8.49 \mathrm{E}-05$ & -0.01078 & -3.9301 \\
GADD45A & 0.000541 & 0.000112 & 0.011251 & 3.862089 \\
\hline
\end{tabular}

Analysis of 102 samples with type 2 diabetes (T2D) versus 87 normoglycemic individuals. A positive $Z$ value implicates increasing gene expression with T2D, adjusted for study effect subjects [36]. At the cellular level, this decrease has been ascribed to a reduction in mitochondrial content and lower oxidative capacity of the mitochondria [36], i.e., this decrease of mitochondrial constituents could either reflect defective mitochondria or decreased number of mitochondria or both. Several potential regulators of mitochondrial mass and function were identified among the 957 age-associated genes in the current study. For example, ENDOG is a protein regulated by PGC1A, shown to interact with the mitochondrial genome to regulate mitochondrial mass [37]. TOMM40 is a crucial subunit of the translocase responsible for import of nuclear-encoded mitochondrial precursor proteins [38], which has previously been associated with aging and with exerciseinduced mitochondrial biogenesis [39]. MRPL4 and MRPL48 are components of the mitochondrial ribosome, responsible for the production of essential oxidative phosphorylation proteins and $\mathrm{CMC} 2$ is required for mitochondrial cytochrome c oxidase assembly [26]. HCCS and TFRC are other proteins associated with aging that are required for proper functioning of the ETC [40, 41]. Among other potential regulators associated with aging are two 


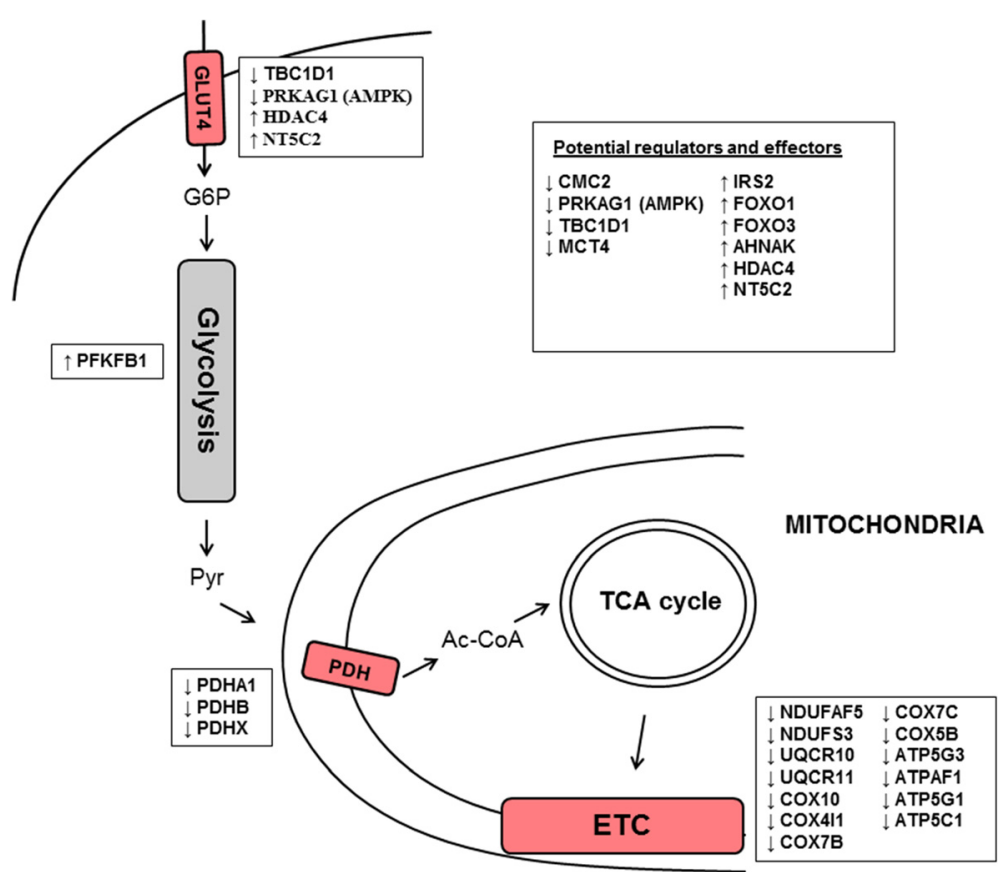

Fig. 3 Schematic illustration of major metabolic effects of aging in human skeletal muscle. A subjectively selected set of effector and regulatory genes from the 957 age-associated genes are shown with their direction of regulation shown with respect to increasing age

forkhead transcription factors, i.e., FOXO1 and FOXO3. Both of these have also previously been implicated for roles in aging, longevity, and muscle atrophy $[42,43]$. In summary, deterioration in skeletal muscle mitochondrial function is already well recognized as a major factor contributing to age-related muscle degeneration [34, 35], and our findings support this claim on a broad molecular level, identifying a large number of potential regulators.

We find that genes that have a function in glucose uptake and energy sensing are strongly affected by aging. For example, we see reduced expression of the $\gamma 1$ regulatory unit of AMPK with increased age. AMPK is a major energy sensor in skeletal muscle, controlling crucial steps of both glucose and lipid metabolism through the ability to sense AMP levels [44]. Reduced AMPK expression is known to result in lower ability of the muscle to utilize glucose through the GLUT4 transporter and to reduce the effectiveness of exercise as a stimulant of glucose uptake and ATP generation through glycolysis, with negative effects on glycemic control and regeneration of muscle mass. Induction of $\mathrm{NT} 5 \mathrm{C} 2$ expression with increased age is a possible explanation to the age-associated reduction in AMPK activity, which in turn could be an important contributing factor to reduced mitochondrial function associated with aging [45]. Silencing of NT5C2 expression in cultured human myotubes increased the AMP/ATP ratio and AMPK activity and promoted palmitate oxidation and glucose transport [46], and endogenous expression of $\mathrm{NT} 5 \mathrm{C} 2$ is known to inhibit basal lipid oxidation and glucose transport in skeletal muscle. AMPK, in turn, appears to regulate GLUT4 expression via the HDAC4/5-MEF2 axis [47], and in this study, we detected an increased expression of HDAC4 with increased age. The importance of the regulation of GLUT4 levels by AMPK in skeletal muscle is supported by this study showing regulated levels of $\mathrm{NT} 5 \mathrm{C} 2$ with age, which can be reversed by physical capacity. Together, the interactions between age-associated changes in gene expression in these key pathways may explain the reduced ability to both generate energy for muscle contraction during exercise and to utilize circulating glucose in the aging muscle.

\section{Muscle aging and physical capacity}

Strikingly, we find that genes that are associated with both aging and physical capacity are largely counteracting. The presented data thereby support efforts to maintain high physical fitness in an aging population to counteract negative effects on mitochondrial function [48]. In particular, we hypothesize that SOCS2 and FEZ2, which show significant associations with age, BMI, and physical capacity and acting in the same direction for BMI and age but in the opposite direction for increasing physical capacity, have key regulatory functions in processes that link these three factors. SOCS2 interacts strongly with the activated IGF1R and may play a regulatory role in IGF1 receptor signaling [49]. Age-associated difference in the mRNA level of SOCS2 has previously been demonstrated in muscle from rat, where it was suggested to reflect resistance to the 
effect of growth hormone [50]. Also, an acute bout of resistance exercise is capable of upregulating SOCS2 in human skeletal muscle [51]. FEZ2 is to our knowledge a novel age-associated gene, the expression of which was altered in the opposite direction with physical capacity.

\section{Conclusions}

We show that through a strong manual curation effort, we could increase the combinability and utility of public data, deriving the until now largest study on aging in human skeletal muscle. This skeletal muscle compendium is publicly available, with applications for further studies on transcriptional regulation in skeletal muscle for a number of physiological and biological questions. Overall, our results paint a convoluted picture with many age-related pathways affecting a wide range of fundamental cellular processes. These results support that mitochondrial dysfunction is a major age-related factor and also highlight the beneficial effects of maintaining a high physical capacity for prevention of age-related sarcopenia.

\section{Additional files}

Additional file 1: Supplementary material Figure S $51-4$ and Table S1 (DOCX $385 \mathrm{~kb}$ )

Additional file 2: Table S2 957 genes significantly associated with age across 340 samples (XLSX $257 \mathrm{~kb}$ )

\begin{abstract}
Abbreviations
ACTA1: alpha 1 actin; AHNAK: AHNAK nucleoprotein, desmoyokin; CMC2: C-X(9)-C motif containing 2; DLEU1: deleted in lymphocytic leukemia 1; ETC.: electron transport chain; FDR: false discovery rate; FEZ2: fasciculation and elongation protein zeta 2; GAPDH: glyceraldehyde-3-phosphate dehydrogenase; GSEA: gene set enrichment analysis; H3F3B: H3 histone, family 3B; HOXB2: homeobox B2; MB: myoglobin; mTOR: mammalian target of rapamycin; mTORC1: mTOR complex I; NGT: normal glucose tolerance; OXPHOS: mitochondrial oxidative phosphorylation; PCA: principal component analysis; PDC: pyruvate dehydrogenase complex; PFKFB1: 6-phosphofructo-2-kinase/fructose-2,6-biphosphatase 1; PGC1a: peroxisome proliferator-activated receptor gamma coactivator alpha; RPA: robust probabilistic averaging; SOCS2: suppressor of cytokine signaling 2; T2D: type 2 diabetes; TBC1D1: TBC1 domain family member 1; TCA: tricarboxylic acid cycle; $\mathrm{VO}_{2 \text { MAX: }}$ maximal oxygen consumption.
\end{abstract}

\section{Competing interests}

The authors declare that they have no competing interests.

\section{Authors' contributions}

$J S$ and $C E$ acquired the data, performed the analysis, and interpreted the data. NO, KS, LL, and AB performed the analysis and interpreted the data. LG designed the study and interpreted the data. JR and $\mathrm{OH}$ designed the study, performed the analysis, and interpreted the data. All authors have been involved in drafting the manuscript and/or revising it critically. All authors read and approved the final manuscript.

\section{Acknowledgements}

This work has been funded by the Swedish Research Council Linnaeus grant: Lund University Diabetes Centre (Dnr 349-2006-237) and SFO Exodiab (Dnr 2009-1039), European Research Council (ERC)—Advanced Researcher Grant (GA 269045), NuGo, ALF, the Crafoord Foundation, SV Skånes diabetes förening, the Wallenberg Foundation, the Novo Nordisk Foundation, EXGENESIS, UMAS Fonder, Magn. Bergvalls Stiftelse, Syskonen
Svenssons Fond, the Swedish Diabetes Research Foundation (2009-060), Swedish research council, the European Community's Seventh Framework Programme (FP7/2007-2013), and ENGAGE (HEALTH-F4-2007-201413). The funding agencies had no influence on the design of the study, the collection or analysis of the data, or any other aspect of the presented work.

\section{Author details}

${ }^{1}$ European Molecular Biology Laboratory-European Bioinformatics Institute, Wellcome Trust Genome Campus Hinxton, Cambridge CB10 1SD, UK. ${ }^{2}$ Lund University Diabetes Center, Department of Clinical Sciences, Diabetes and Endocrinology, Skåne University Hospital Malmö, Lund University, Malmö 20502, Sweden. ${ }^{3}$ Department of Veterinary Biosciences, University of Helsinki, PO Box 66, Fl-00014 Helsinki, Finland. ${ }^{4}$ Swedish Winter Sports Research Centre, Department of Health Sciences, Mid Sweden University, SE-83125 Östersund, Sweden. ${ }^{5}$ Department of Immunology, Genetics and Pathology, Science for Life Laboratory, Rudbeck Laboratory, Uppsala University, 75185 Uppsala, Sweden.

Received: 2 July 2015 Accepted: 28 September 2015

Published online: 09 October 2015

\section{References}

1. Delmonico MJ, Harris TB, Visser M, Park SW, Conroy MB, Velasquez-Mieyer P, et al. Longitudinal study of muscle strength, quality, and adipose tissue infiltration. Am J Clin Nutr. 2009;90(6):1579-85. doi:10.3945/ajcn.2009.28047.

2. Dirks AJ, Hofer T, Marzetti E, Pahor M, Leeuwenburgh C. Mitochondrial DNA mutations, energy metabolism and apoptosis in aging muscle. Ageing Res Rev. 2006;5(2):179-95. doi:10.1016/j.arr.2006.03.002.

3. Kim TN, Choi KM. Sarcopenia: definition, epidemiology, and pathophysiology. J Bone Metab. 2013;20(1):1-10. doi:10.11005/jbm.2013.20.1.1.

4. Goodpaster BH, Park SW, Harris TB, Kritchevsky SB, Nevitt M, Schwartz AV, et al. The loss of skeletal muscle strength, mass, and quality in older adults: the health, aging and body composition study. J Gerontol A Biol Sci Med Sci. 2006;61(10):1059-64.

5. Zahn JM, Sonu R, Vogel H, Crane E, Mazan-Mamczarz K, Rabkin R, et al. Transcriptional profiling of aging in human muscle reveals a common aging signature. PLoS Genet. 2006;2(7):e115. doi:10.1371/journal.pgen.0020115.eor.

6. de Magalhães JP, Curado J, Church GM. Meta-analysis of age-related gene expression profiles identifies common signatures of aging. Bioinformatics. 2009;25(7):875-81. doi:10.1093/bioinformatics/btp073.

7. Bua E, Johnson J, Herbst A, Delong B, McKenzie D, Salamat S, et al. Mitochondrial DNA-deletion mutations accumulate intracellularly to detrimental levels in aged human skeletal muscle fibers. Am J Hum Genet. 2006;79(3):469-80. doi:10.1086/507132.

8. Austin S, St-Pierre J. PGC1a and mitochondrial metabolism-emerging concepts and relevance in ageing and neurodegenerative disorders. J Cell Sci. 2012;125(Pt 21):4963-71. doi:10.1242/jcs.113662.

9. Mootha VK, Lindgren CM, Eriksson KF, Subramanian A, Sihag S, Lehar J, et al. PGC-1alpha-responsive genes involved in oxidative phosphorylation are coordinately downregulated in human diabetes. Nat Genet. 2003;34(3):267-73.

10. Patti ME, Butte AJ, Crunkhorn S, Cusi K, Berria R, Kashyap S, et al. Coordinated reduction of genes of oxidative metabolism in humans with insulin resistance and diabetes: Potential role of PGC1 and NRF1. Proc Natl Acad Sci U S A. 2003;100(14):8466-71. doi:10.1073/pnas.1032913100.

11. Bodine SC, Stitt TN, Gonzalez M, Kline WO, Stover GL, Bauerlein R, et al. Akt/mTOR pathway is a crucial regulator of skeletal muscle hypertrophy and can prevent muscle atrophy in vivo. Nat Cell Biol. 2001;3(11):1014-9. doi:10.1038/ncb1101-1014.

12. Lee MN, Ha SH, Kim J, Koh A, Lee CS, Kim JH, et al. Glycolytic flux signals to MTOR through glyceraldehyde-3-phosphate dehydrogenasemediated regulation of Rheb. Mol Cell Biol. 2009;29(14):3991-4001. doi:10.1128/MCB.00165-09.

13. Lukk M, Kapushesky M, Nikkilä J, Parkinson H, Goncalves A, Huber W, et al. A global map of human gene expression. Nat Biotechnol. 2010;28(4):322-4. doi:10.1038/nbt0410-322.

14. Zheng-Bradley X, Rung J, Parkinson H, Brazma A. Large scale comparison of global gene expression patterns in human and mouse. Genome Biol. 2010;11(12):R124. doi:10.1186/gb-2010-11-12-r124. 
15. Ojala KA, Kilpinen SK, Kallioniemi OP. Classification of unknown primary tumors with a data-driven method based on a large microarray reference database. Genome Med. 2011;3(9):63. doi:10.1186/gm279.

16. Kilpinen S, Autio R, Ojala K, Iljin K, Bucher E, Sara H, et al. Systematic bioinformatic analysis of expression levels of 17,330 human genes across 9,783 samples from 175 types of healthy and pathological tissues. Genome Biol. 2008;9(9):R139. doi:10.1186/gb-2008-9-9-r139.

17. Rung J, Brazma A. Reuse of public genome-wide gene expression data. Nat Rev Genet. 2013;14(2):89-99. doi:10.1038/nrg3394.

18. Rustici G, Kolesnikov N, Brandizi M, Burdett T, Dylag M, Emam I, et al. ArrayExpress update-trends in database growth and links to data analysis tools. Nucleic Acids Res. 2013;41(Database issue):D987-90. doi:10.1093/nar/gks1174.

19. Lahti L, Elo LL, Aittokallio T, Kaski S. Probabilistic analysis of probe reliability in differential gene expression studies with short oligonucleotide arrays. IEEE/ACM Trans Comput Biol Bioinform. 2011;8(1):217-25. doi:10.1109/TCBB.2009.38.

20. Lahti L, Torrente A, Elo LL, Brazma A, Rung J. A fully scalable online preprocessing algorithm for short oligonucleotide microarray atlases. Nucleic Acids Res. 2013;41(10), e110. doi:10.1093/nar/gkt229.

21. Kauffmann A, Gentleman R, Huber W. arrayQualityMetrics-a bioconductor package for quality assessment of microarray data. Bioinformatics. 2009;25(3):415-6. doi:10.1093/bioinformatics/btn647.

22. GTEx Consortium. The Genotype-Tissue Expression (GTEx) project. Nat Genet. 2013;45(6):580-5. 10.1038/ng.2653.

23. Robinson MD, Oshlack A. A scaling normalization method for differential expression analysis of RNA-seq data. Genome Biol. 2010;11(3):R25. doi:10.1186/gb-2010-11-3-r25

24. Rudy J, Valafar F. Empirical comparison of cross-platform normalization methods for gene expression data. BMC Bioinformatics. 2011;12:467. doi:10.1186/1471-2105-12-467.

25. Parikh $H$, Nilsson E, Ling C, Poulsen $P$, Almgren $P$, Nittby $H$, et al. Molecular correlates for maximal oxygen uptake and type 1 fibers. Am J Physiol Endocrinol Metab. 2008;294(6):E1152-9. doi:10.1152/ajpendo.90255.2008.

26. Horn D, Zhou W, Trevisson E, Al-Ali H, Harris TK, Salviati L, et al. The conserved mitochondrial twin $\mathrm{CX9C}$ protein $\mathrm{Cmc2}$ is a $\mathrm{Cmc} 1$ homologue essential for cytochrome c oxidase biogenesis. J Biol Chem. 2010:285(20):15088-99. doi:10.1074/jbc.M110.104786.

27. Szekeres F, Chadt A, Tom RZ, Deshmukh AS, Chibalin AV, Björnholm M, et al The Rab-GTPase-activating protein TBC1D1 regulates skeletal muscle glucose metabolism. Am J Physiol Endocrinol Metab. 2012;303(4):E524-33. doi:10.1152/ajpendo.00605.2011.

28. An D, Toyoda T, Taylor EB, Yu H, Fujii N, Hirshman MF, et al. TBC1D1 regulates insulin- and contraction-induced glucose transport in mouse skeletal muscle. Diabetes. 2010;59(6):1358-65. doi:10.2337/db09-1266.

29. Wang N, Yang C, Xie F, Sun L, Su X, Wang Y, et al. Gadd45a: a novel diabetes-associated gene potentially linking diabetic cardiomyopathy and baroreflex dysfunction. PLoS ONE. 2012;7(12), e49077. doi:10.1371/journal.pone.0049077.

30. Sporrer D, Weber M, Wanninger J, Weigert J, Neumeier M, Stögbauer F, et al. Adiponectin downregulates CD163 whose cellular and soluble forms are elevated in obesity. Eur J Clin Invest. 2009;39(8):671-9. doi:10.1111/j.1365-2362.2009.02170.x.

31. Bongers KS, Fox DK, Ebert SM, Kunkel SD, Dyle MC, Bullard SA, et al. Skeletal muscle denervation causes skeletal muscle atrophy through a pathway that involves both Gadd45a and HDAC4. Am J Physiol Endocrinol Metab. 2013;305(7):E907-15. doi:10.1152/ajpendo.00380.2013.

32. Cheng $Y$, Wang $Y$, Li Y, Deng $Y$, Hu J, Mo X, et al. A novel human gene ZNF415 with five isoforms inhibits AP-1- and p53-mediated transcriptional activity. Biochem Biophys Res Commun. 2006;351(1):33-9. doi:10.1016/j.bbrc.2006.09.161.

33. Møller HJ, Frikke-Schmidt R, Moestrup SK, Nordestgaard BG, Tybjærg-Hansen A. Serum soluble CD163 predicts risk of type 2 diabetes in the general population. Clin Chem. 2011;57(2):291-7. doi:10.1373/clinchem.2010.154724.

34. Short KR, Bigelow ML, Kahl J, Singh R, Coenen-Schimke J, Raghavakaimal $\mathrm{S}$, et al. Decline in skeletal muscle mitochondrial function with aging in humans. Proc Natl Acad Sci U S A. 2005;102(15):5618-23. doi:10.1073/pnas.0501559102.

35. Johnson ML, Robinson MM, Nair KS. Skeletal muscle aging and the mitochondrion. Trends Endocrinol Metab. 2013;24(5):247-56. doi:10.1016/j.tem.2012.12.003.
36. Conley KE, Jubrias SA, Esselman PC. Oxidative capacity and ageing in human muscle. J Physiol. 2000;526(Pt 1):203-10.

37. McDermott-Roe C, Ye J, Ahmed R, Sun XM, Serafín A, Ware J, et al. Endonuclease $\mathrm{G}$ is a novel determinant of cardiac hypertrophy and mitochondrial function. Nature. 2011;478(7367):114-8. doi:10.1038/nature10490.

38. Humphries AD, Streimann IC, Stojanovski D, Johnston AJ, Yano M, Hoogenraad NJ, et al. Dissection of the mitochondrial import and assembly pathway for human Tom40. J Biol Chem. 2005;280(12):11535-43. doi:10.1074/jbc.M413816200

39. Joseph AM, Ljubicic V, Adhihetty PJ, Hood DA. Biogenesis of the mitochondrial Tom40 channel in skeletal muscle from aged animals and its adaptability to chronic contractile activity. Am J Physiol Cell Physiol. 2010;298(6):C1308-14. doi:10.1152/ajpcell.00644.2008.

40. Schaefer L, Ballabio A, Zoghbi HY. Cloning and characterization of a putative human holocytochrome c-type synthetase gene (HCCS) isolated from the critical region for microphthalmia with linear skin defects (MLS). Genomics. 1996;34(2):166-72. doi:10.1006/geno.1996.0261.

41. Ishii KA, Fumoto T, Iwai K, Takeshita S, Ito M, Shimohata N, et al. Coordination of PGC-1beta and iron uptake in mitochondrial biogenesis and osteoclast activation. Nat Med. 2009;15(3):259-66. doi:10.1038/nm.1910.

42. Willcox BJ, Donlon TA, He Q, Chen R, Grove JS, Yano K, et al. FOXO3A genotype is strongly associated with human longevity. Proc Natl Acad Sci U S A. 2008;105(37):13987-92. doi:10.1073/pnas.0801030105.

43. Sandri M, Sandri C, Gilbert A, Skurk C, Calabria E, Picard A, et al. Foxo transcription factors induce the atrophy-related ubiquitin ligase atrogin-1 and cause skeletal muscle atrophy. Cell. 2004;117(3):399-412.

44. Hamilton SR, Stapleton D, O'Donnell JB, Kung JT, Dalal SR, Kemp BE, et al. An activating mutation in the gammal subunit of the AMP-activated protein kinase. FEBS Lett. 2001;500(3):163-8.

45. Reznick RM, Zong H, Li J, Morino K, Moore IK, Yu HJ, et al. Aging-associated reductions in AMP-activated protein kinase activity and mitochondrial biogenesis. Cell Metab. 2007;5(2):151-6. doi:10.1016/j.cmet.2007.01.008.

46. Kulkarni SS, Karlsson HK, Szekeres F, Chibalin AV, Krook A, Zierath JR. Suppression of 5'-nucleotidase enzymes promotes AMP-activated protein kinase (AMPK) phosphorylation and metabolism in human and mouse skeletal muscle. J Biol Chem. 2011;286(40):34567-74. doi:10.1074/jbc.M111.268292.

47. Richter EA, Hargreaves M. Exercise, GLUT4, and skeletal muscle glucose uptake. Physiol Rev. 2013;93(3):993-1017. doi:10.1152/physrev.00038.2012.

48. Broskey NT, Greggio C, Boss A, Boutant M, Dwyer A, Schlueter L, et al. Skeletal muscle mitochondria in the elderly: effects of physical fitness and exercise training. J Clin Endocrinol Metab. 2014;99(5):1852-61. doi:10.1210/jc.2013-3983

49. Dey BR, Spence SL, Nissley P, Furlanetto RW. Interaction of human suppressor of cytokine signaling (SOCS)-2 with the insulin-like growth factor-I receptor. J Biol Chem. 1998;273(37):24095-101.

50. Haddad F, Adams GR. Aging-sensitive cellular and molecular mechanisms associated with skeletal muscle hypertrophy. J Appl Physiol (1985). 2006;100(4):1188-203. doi:10.1152/japplphysiol.01227.2005.

51. Buford TW, Cooke MB, Willoughby DS. Resistance exercise-induced changes of inflammatory gene expression within human skeletal muscle. Eur J Appl Physiol. 2009;107(4):463-71. doi:10.1007/s00421-009-1145-z.

\section{Submit your next manuscript to BioMed Central and take full advantage of:}

- Convenient online submission

- Thorough peer review

- No space constraints or color figure charges

- Immediate publication on acceptance

- Inclusion in PubMed, CAS, Scopus and Google Scholar

- Research which is freely available for redistribution 